\title{
Destabilization of Abnormal Methylation Enzymes: Nature's Way to Eradicate Cancer Stem Cells
}

\author{
Ming C Liau'* ${ }^{*}$, Jai Hyun Kim² and John P. Fruehauf ${ }^{2}$ \\ ${ }^{1}$ CDA Therapeutics, USA \\ ${ }^{2}$ Chao Family Comprehensive Cancer Center, University of California, Irvine, USA
}

*Corresponding author: Ming C Liau, CDA Therapeutics, Inc. 2384 Tubbs Dr., Tustin, CA, 92782, USA.

Received Date: October 23, 2019

Published Date: November 01, 2019

\section{Cancer Stem Cells (CSCs): The Primary Cause of Cancer Treatment Failure}

Cancer therapy is dominated by cytotoxic agents that act via mechanisms that damage DNA and activate apoptotic pathways. While cytotoxic agents have been moderately effective to eliminate symptoms and to extend the life span of cancer patients, this approach rarely results in cure. Therefore, cancer related mortality remains as a leading cause of death in most countries.

Over that past decade it has becomes clear that CSCs stand in the way of successful curative results from conventional cytotoxic cell killing to put cancer away. The transition of the tumor to one containing predominantly CSCs is now thought to be a primary cause of treatment failure [1-5]. Many biological characteristics that enable cancer progression are attributable to CSCs, including angiogenesis, metastasis, and drug resistance. CSCs are resistant to both cytotoxic drugs and radiation in part because these cells overexpress ATP binding cassette drug pumps that effectively exclude cytotoxic drugs and have activation of anti-apoptosis programs that negate the pro-apoptotic signals activated by DNA damaging agents [6-9]. CSCs share much in common with normal progenitor stem cells with respect to cell features and biological missions. Their biological missions are to repair and to meet the replacement needs of the organ or tissue. When cancer cells are destroyed by cytotoxic drugs or radiation, CSCs proliferate to replace the dying cancer cells and the tumor regrows. Eventually CSCs become the dominant tumor component and their unchecked growth claims the life of the patient. Therefore, eventual successful cancer therapies must rely on the elimination of not only cancer cells, but also the subpopulation of CSCs. Alternative therapeutic strategies are needed to eradicate CSCs.
Methylation Enzymes (MEs) Function as A Switch to Turn on to Cell Replication and to Turn Off to Terminal Differentiation (TD)

MEs play a critical role on the regulation of cell replication and differentiation. DNA methylation controls the expression of tissue specific genes Racanelli AC, et al. [10], and pre-rRNA ribose methylation controls the production of ribosomes Liau MC et al. [11], which in turn dictates the commitment of cells to initiate replication [12]. If enhanced production of ribosomes is locked in place, it becomes a factor to drive carcinogenesis [13]. Biological methylation is mediated by a ternary enzyme complex consisting of methionine adenosyl transferase (MAT), methyltransferase (MT), and S-adenosylhomocysteine hydrolase (SAHH) [14,15]. These enzymes must be in a ternary enzyme complex to become stable and functional. In the monomeric state, individual enzymes are quickly inactivated. SAHH is the most unstable enzyme, followed by MT, and then MAT. Their stability corresponds very well to their molecular size. MTs in the monomeric state have a greater tendency to be converted into nucleases to trigger apoptosis. The conversion of MTs into nucleases can be prevented by keeping MTs in the dimeric state with SAHH, or by the use of inhibitors of MTs to resist protease modification. SAHH requires a steroid factor to assume a configuration favorable for the formation of a dimeric enzyme complex with MT, which can then associate with MAT to form the ternary enzyme complex. In steroid hormone target tissues, such as prostate and breast, steroid hormones are the stabilizing factor of SAHH. Other tissues require similar steroid factors generated by growth signals to stabilize SAHH [16]. In normal cells, steroid factors are the dominant factors to modulate MEs. 
In cancer cells and telomerase expressing primitive stem cells, such as embryonic stem cells and progenitor stem cells, MAT is associated with telomerase (hTERT) Liau MC et al. [17], which promotes increased stability of the ME complex. The association of $\mathrm{MAT}^{\mathrm{L}}$, which is the normal isozyme of MAT, with telomerase changes the kinetic property of $\mathrm{MAT}^{\mathrm{L}}$ and the regulation of MEs. $\mathrm{K}_{\mathrm{m}}$ values of $\mathrm{MAT}^{\mathrm{L}}$ and $\mathrm{MAT}^{\mathrm{LT}}$, the telomerase associated cancer isozyme, are $3 \mu \mathrm{M}$ and $20 \mu \mathrm{M}$ methionine, respectively, and those of SAHH ${ }^{\mathrm{L}}$ and $\mathrm{SAHH}^{\mathrm{LT}}$ are $0.3 \mu \mathrm{M}$ and $2 \mu \mathrm{M}$ adenosine, respectively $[14,15,17]$. The increased $K_{m}$ value of MAT ${ }^{\text {LT }}$ suggests that MEs of cancer cells have elevated levels of bound S-adenosylmethionine (AdoMet). According to Prudova A, et al. [18], the binding of AdoMet to a protein could protect that protein against protease digestion. It appears then that the increased pool size of AdoMet in cancer cells contributes to the stability and activity of MEs to promote malignant growth. Chiba P, et al. [19] found that the pool sizes of AdoMet and S-adenosylhomocysteine (AdoHcy) shrunk greatly when cancer cells were induced to undergo TD. This finding strongly supports our hypothesis that the association of telomerase with MEs greatly increases the stability and the activity of MEs of cancer cells, thereby suppressing the hypomethylation of nucleic acids necessary for cells to undergo TD $[15,20]$. Thus, it is very clear that abnormal MEs play a critical role in the evolution and progression of cancer.

\section{Abnormal MEs in Cancer}

The association of telomerase with MEs locks MEs in an extremely stable and active state. Their increased enzyme function expands the methyl-group pool, blocking cell differentiation. In addition, telomerase activity is enhanced when it resides in the ME complex, enabling increased telomere maintenance and limitless proliferative capacity.

There is another way to achieve DNA demethylation to bypass the differentiation blockade created by abnormal MEs. Ten-eleven translocation protein (Tet) dioxygenases carries out oxidation of 5-methylcytidine $(5-\mathrm{mC})$ to generate 5-hydroxymethycytosine (5hmC), 5-formylcytosine (5fC) and 5-carboxylcytosine (5-caC) [21-24]. Five-caC is finally replaced by cytosine by thymine DNA glycosylase and base excision repair $[25,26]$. Five-hmC is the stable intermediate in the oxidative demethylation of 5-mC [27].

Three Tet dioxygenases have been identified. Tet 1 preferentially acts on 5-mC located at transcriptional start sites, whereas Tet 2 preferentially acts on 5-mC located in the $\mathrm{CpG}$ rich domains in the gene body [28]. Tet 3 is expressed at very high level in oocytes and zygotes, but rapidly declines at the two-cell stage. Tet 3 is responsible for the elimination of paternal 5-mC in fertilized oocytes [29]. Tet enzymes are very active in embryonic stem cells to direct embryonic lineage differentiation [30, 31]. These enzymes are frequently mutated to become dysfunctional or silenced in cancer cells [32-35]. The expression and function of Tet enzymes marks a critical difference between cancer cells and primitive normal stem cells. Blockade of differentiation is apparently a normal process to build up cell mass for the development of fetus in the case of embryonic stem cells, or for wound healing in the case of progenitor stem cells. Cancer cells lose the mechanism to break through the blockade of differentiation created by abnormal MEs. Consequently destabilization of abnormal MEs is an attractive option to induce TD of cancer cells.

\section{Destabilization of Abnormal MEs as an Effective Approach for Cancer Therapy}

Blockade of differentiation by abnormal MEs may play a more fundamental role in CSCs than the activation of oncogenes or inactivation of suppressor genes. After all, oncogenes and suppressor genes are cell cycle regulatory genes, which have important roles to play when cell are replicating. They have no role to play when replicating cells are diverted to terminally differentiated cells. In one stroke, destabilization of abnormal MEs can induce terminal differentiation to wipe out all damages created by oncogenes and mutated tumor suppressor genes, which have attracted so much attention in the cancer field.

The successful therapy of acute promyelocytic leukemia with all-trans-retinoic acid (ATRA) must be considered as the best example of differentiation therapy in cancer, which was accomplished by destabilization of abnormal MEs. The therapy yields a stunning complete response rate of $\sim 90 \%$ [36]. Remissions, however, are transient. Most patients relapse within a year [37,38]. The combination of ATRA and arsenic trioxide produces a more satisfactory, long lasting remission [38]. ATRA is a differentiation inducer (DI) and arsenic trioxide is a differentiation helper inducer (DHI) [16]. DIs are chemicals capable of eliminating the association of telomerase with abnormal MEs, leading to their destabilization and cellular differentiation [39]. DHIs are inhibitors of the individual enzymes of the ternary MEs [40]. DHIs by themselves at very high concentrations can also achieve significant induction of TD. At concentrations inactive as DIs, DHIs can greatly potentiate the activity of DIs. Their helping role in modulating the ME complex is a key feature of DHIs. DIs are much more effective than DHIs to induce TD. DIs alone, however, cannot push all cancer cells to complete TD. But in the presence of DHIs, complete TD can be accomplished [16]. Therefore, it is essential to have both DI and DHI agents in combination to make a perfect therapeutic for the induction of TD. Arsenic trioxide is very toxic. It is also a potent carcinogen [41]. It is advisable to replace arsenic trioxide with the more effective and less toxic DHIs we have described [16, 42].

DHIs alone can be very effective for cancer therapy too. Imatinib mesylate is the standard of care for chronic myeloid leukemia [43]. The therapeutic efficacy of imatinib mesylate on chronic myeloid leukemia is almost as good as ATRA plus arsenic trioxide on APL, and remissions are long lasting. This is another example of how targeting and destabilizing abnormal MEs can be an effective cancer therapy. We have demonstrated that signal transduction inhibitors (STIs) such as imatinib mesylate were excellent DHIs [16]. DHIs, however, are not very effective at achieving induction of TD by themselves. DIs are produced endogenously Liau MC et al. [42], but cancer patients tend to lose their DIs via renal losses. Higher 
levels of immune related cytokines in cancer patients leads to leaky nephron vascular tufts that fail to retain the lower molecular weight DIs. Exogenous replacement of DIs, however, can compensate for the deficiency of natural DIs to achieve effective therapy.

Phenylbutyrate was our initial finding of an agent with DHI activity. However, this agent was only moderately active, requiring $\mathrm{mM}$ concentrations to function [40]. Nevertheless, it has demonstrated therapeutic efficacy on often untreatable brain tumors $[44,45]$. It's benefits were enhanced when used in combination with STIs [46,47], which were effective in $\mu \mathrm{M}$ concentrations [16]. It is remarkable that an ordinary chemical such as phenylbutyrate could in some cases cure primary glioblastoma brain tumors. This suggests that focusing on abnormal MEs as a target of CSCs presents a real opportunity to improve cancer outcomes. DHIs are easily available and relatively non-toxic. DHIs, such as dietary polyphenols, are frequently suggested for chemoprevention of cancer [48-51].

\section{Destabilization of Abnormal MEs to eradicate CSCs}

In 1987, Liau MC et al. [52] introduced the concept of chemosurveillance as a natural defense mechanism against cancer. This hypothesis was based on the observation that healthy people could maintain a steady level of hydrophobic metabolites in their plasma, whereas cancer patients tended to show deficiency of such metabolites due to excessive urinary excretion [53]. Among such metabolites were chemicals active as DIs and DHIs [39,40]. The implication is that healthy people have enough DIs and DHIs in their circulation to keep a check on the evolution of cancer cells, whereas in cancer patients a lack of DIs and DHIs depresses their capacity to stop the replication of cancer cells. The evolution of cancer in the case of myelodysplastic syndrome (MDS) strongly supports the validity of this hypothesis.

MDS often starts with a display of an immunological disorder [54], which prompts the local production of inflammatory cytokines. Among such cytokines, TNF is the critical factor related to the development of MDS [55]. It causes excessive apoptosis of bone marrow stem cells, severely affecting the ability of the patient to produce hematopoietic cells such as erythrocytes, platelets, and neutrophils. TNF is also named cachectin, because of its causation of cachexia, defined as weight loss and muscle wasting unresponsive to nutrient intake, a syndrome commonly shared by terminal cancer patients. A characteristic disorder of cachexia is the excessive urinary excretion of low molecular weight metabolites because of vascular hyperpermeability caused by TNF [56,57]. As a consequence, chemosurveillance normally operating in healthy people to keep progenitor cells in check becomes dysfunctional, allowing progenitor stem cells to build up in order to replenish unipotent stem cells wiped out by TNF. The high level of telomerase in the peripheral and bone marrow leukocytes in MDS patients is an indication of the widespread multiplication of progenitor stem cells [58,59]. During the course of MDS progression, mutations affecting the enzyme functions of Tet 2, DNMT 3A, IDH 1/2, AXL 1, EXH 2, and RNA splicing enzymes are frequently observed [60-64], which may play significant roles on the evolution of progenitor stem cells to become CSCs [65]. As anemia in MDS patients becomes worse, chromosomal abnormalities such as translocations and deletions characteristic of cancer cells arise and accelerate replication, eventually pushing MDS patients to progress to AML [66-69].

Vidaza and decitabine are the two hypomethylating agents approved for the therapy of MDS in the USA. CDA-2 is the hypomethylating agent approved for the therapy of cancer in China [70], which was first described and characterize by Ming C. Liau [71]. Azacitidine and decitabine achieve DNA hypomethylation by promoting covalent bond formation between DNMT and the azacytosine base incorporated into DNA to titrate out DNMT Santi DV, et al. [72], whereas CDA-2 achieves DNA hypomethylation by converting abnormal MEs into normal enzymes via components active as DIs and DHIs [15,39]. An abbreviated clinical trial of CDA-2 for MDS was conducted on 117 patients in China. Based on two cycles of treatment protocols, CDA- 2 yielded a slightly better therapeutic efficacy under cytological evaluation, and a markedly better therapeutic efficacy under hematological improvement evaluation in comparison to vidaza and decitabine $[73,74]$. It had a superior therapeutic effect and was devoid of serious toxic side effects, whereas vidaza and decitabine are proven carcinogens $[75,76]$, and damaging to DNA [77]. It has been reported that vidaza was very toxic to embryonic cells, particularly against cardiomyocytes [78].

The evolution of CSCs from progenitor stem cells in the case of MDS is a clear-cut illustration of the widely accepted two hit theory of carcinogenesis proposed by Knudson [79]. The expression of telomerase to lock MEs into an abnormally active state represents the first hit on progenitor stem cells. The second hit arises from knock out of Tet enzymes, resulting in progenitor stem cells transforming into CSCs. This is more problematic if it occurs in the presence of depressed chemo surveillance needed to halt the replication of CSCs. The dysfunction of chemo surveillance in the case of MDS is caused by immunological disorders. Immune surveillance does not seem to play an essential role to prevent the formation of CSCs from progenitor stem cells. After all, CSCs and progenitor stem cells are almost indistinguishable. We hypothesize that the sequence of events in the evolution of CSCs into MDS starts from underlying immunological disorders and increased levels of cytokines like TNF that lead to diminished levels of circulating DIs and DHIs, a state permissive for the emergence of CSCs. Immune surveillance and immune checkpoints do have an important role to play in the prevention of cancer, which is to prevent excess release of immune related cytokines, such as TNF. Chemo surveillance plays a more direct role to prevent gene silencing and CSC development. Nature has it own way to offer the best solution for cancer prevention. Destabilization of abnormal MEs is nature's choice for prevention.

Destabilization of abnormal MEs is an effective approach to combat cancer. It turns cancer cells into non-dividing cells which may eventually undergo senescence. Therapy that targets abnormal MEs may be preferred for hematological cancers versus solid tumors. The therapeutic end point of hematological cancers is 
based on the disappearance of cancer cells, whereas the therapeutic end point of solid tumor therapy is tumor regression. CSCs initially make up a minority of the solid tumor population, such that stimulating their differentiation may not impact on tumor size. Disappearance of the circulating CSCs via detection of specific cell surface markers is a more appropriate end point for the assessment of therapeutic effect on CSCs.

\section{Summary}

Cancer cannot be cured unless CSCs are also completely eliminated. CSCs do not respond to chemotherapy and radiotherapy. Therefore, alternative therapies must come into play to target CSCs. Induction of differentiation via destabilization of abnormal MEs presents a new target in the war on CSCs. This may be the nature's choice to keep progenitor cells from evolving into CSCs.

\section{Acknowledgement}

None.

\section{Conflict of interest}

We declare that there is no conflict of interest.

\section{References}

1. Jordan CT, Guzman ML, Noble M (2006) Cancer stem cells. N Eng J Med 355(12): 1253-1261

2. Vermeulen L, Sprick MR, Kemper K, Stassi G, Medema JP (2008) Cancer stem cells-old concepts, new insights. Cell Death Differ 15(6): 947-958.

3. Zabierowski SE, Herlyn M (2008) Melanoma stem cells: the dark seed of melanoma. J Clin Oncol 26(17): 2890-2894.

4. Hemmings C (2010) The elaboration of a critical framework for understanding cancer: the cancer stem cell hypothesis. Pathology 42(2): 105-112.

5. Magee JA, Piskounova E, Morrison SJ (2012) Cancer stem cells: impact, heterogeneity, and uncertainty. Cancer Cell 21(3): 283-296.

6. Zhou S, Schuetz JD, Bunting KD, Colapietro AM, Sampath J, et al. (2001) The ABC transporter Bcrp1/ABCG2 is expressed in a wide variety of stem cells and is a molecular determinant of the side-population phenotype. Nat Med 7(9): 1028-1034.

7. Zhang M, Atkinson RL, Rosen JM (2010) Selective targeting of radiation resistant tumor initiating cells. Proc Natl Acad Sci USA 107(8): 35223527.

8. Moitra K, Lou H, Dean M (2011) Multidrug efflux pumps and cancer stem cells: insights into multidrug resistance and therapeutic development. Clin Pharmacol Ther 89(4): 491-502.

9. Frame FM, Maitland NJ (2011) Cancer stem cells, model of study and implication of therapy resistant mechanisms. Adv Exp Med Biol 720: 105-118

10. Racanelli AC, Turner FB, Xie LY, Taylor SM, Moran RG (2008) A mouse gene that coordinates epigenetic controls and transcriptional interference to achieve tissue-specific expression. Mol Cell Biol 28(2): 836-848.

11. Liau MC, Hunt ME, Hurlbert RB (1976) Role of ribosomal RNA methylases in the regulation of ribosome production. Biochemistry 15(14): 31583164.

12. Bernstein KA, Bleichert F, Bean JM, Cross FR, Baserga SJ (2007) Ribosome biogenesis is sensed at the start cell cycle check point. Mol Cell Biol 18(3): 953-964.

13. Justilien V, Ali SA, Jamieson L, Yin N, Cox AD, et al. (2017) Ect-2 dependent rRNA synthesis is required for KRAS-TRP53-driven lung adenocarcinoma. Cancer Cell 31(2): 256-269.
14. Liau MC, Chang CF, Saunders GF, Tsai YH (1981) S-Adenosylhomocysteine hydrolases as the primary target enzymes in androgen regulation of methylation complexes. Arch Biochem Biophys; 208(1): 261-272.

15. Liau MC (2004) Abnormal methylation enzymes: a selective molecular target for differentiation therapy of cancer. Chin Pharm J 56(2): 57-67.

16. Liau MC Kim JH, Fruehauf JP (2019) Potentiation of ATRA activity in HL-60 cells by targeting methylation enzymes. Pharmacol Pharmaceu Pharmacovigi 3: 9-17.

17. Liau MC, Zhuang P, Chiou GCP (2010) Identification of the tumor factor of abnormal methylation enzymes as the catalytic subunit of telomerase. Chin Oncol Cancer Res 7(2): 86-96.

18. Prudova A, Bauman Z, Braun A, Vitvitsky V, Lu SC, et el. (2006) $S$-Adenosylmethionine stabilizes $\beta$-cystathionase and modulate redox capacity. Proc Natl Acad Sci USA 103(17): 6489-6494.

19. Chiba P, Wallner C, Kaizer E (1988) S-Adenosylmethionine metabolism in HL-60 cells: effect of cell cycle and differentiation. Biochim Biophys Acta 971(1): 38-45.

20. Liau MC, Lee SS, Burzynski SR (1989) Hypomethylation of nucleic acids: a key to the induction of terminal differentiation. Intl J Exp Clin Chemother 2: 187-199.

21. Tahiliani M, Koh KP, Shen Y, Lawler A, Bandukwala H, et al. (2009) Conversion of 5-methylcytosine to 5-hydroxymethylcytosine in mammalian DNA by MLL partner TET 1. Science 324(5929): 930-935.

22. Ito S, Shen L, Dai Q, Wu SC, Collins LB, et al. (2011) Tet protein can convert 5-methylcytosine to 5-formlcytosine and 5-carboxylcytoisine. Science 333(6047): 1300-1303.

23. Shen L, Sing CX, He C, Zhang Y (2014) Mechanism and function of oxidation reversal of DNA and RNA methylation. Annu Rev Biochem 83: 585-614.

24. Wu X, Zhang Y (2017) TET-mediated active DNA demethylation: mechanism, function and beyond. Nat Rev Genet 18(9): 517-534.

25. He YF, Li BZ, Li Z, Liu P, Wang Y, et al. (2011) Tet-mediated formation of 5 -carboxyl-cytosine and its excision by TDG in mammalian DNA. Science 333(6047): 1303-1307.

26. Maiti A, Drohat AC (2011) Thymine DNA glycosylase can rapidly excise 5-formylcytosine and 5-carboxylcytosine: potential implication for active demethylation of CpG sites. J Biol Chem 286(41): 35334-35338.

27. Hu L, Lu J, Cheng J, Rao Q, Li Z, et al. (2015) Structural insight into substrate preference for TET-medicated oxidation. Nature 527(7576): 118-122.

28. Huang Y, Charez L, Chang X, Wang X, Pastor WA, et al. (2014) Distinct role of the methylcytosine oxidases Tet 1 and Tet 2 in mouse embryonic stem cells. Proc Natl Acad Sci USA 111(4): 1361-1366.

29. Igbal K, Jin SG, Pfeifer GP, Szabo PE (2011) Reprogramming of the paternal genome upon fertilization involves genome-wide oxidation of 5-methylcytosine. Proc Natl Acad Sci USA 108(9): 3642-3647.

30. Ficz G, Branco MR, Seisenberger S, Santos F, Krueger F, et al. (2011) Dynamic regulation of 5-hydroxymethylcytosine mouse ES cells and during differentiation. Nature 473(7347): 398-403.

31. Munfort A, Wutz A (2013) Breathing-in epigenetic change with vitamin. EMBO Rep 14(4): 337-346.

32. Haffner MC, Chaux A, Meeker AK, Esopi DM, Gerber J, et al. (2011) Global 5-hydroxymethylcytosine content is significantly reduced in tissue stem/progenitor cell compartments and in human cancers. Oncotarget 2(8): 627-637.

33. Kudo Y, Tateishi K, Yamamoto K, Yamamoto S, Asaoka Y, et al (2012) Loss of 5-hydroxymethylcytosine is accompanied with malignant cellular transformation. Cancer Sci 103(4): 670-676.

34. Ficz Gm, Gibben JG (2014) Loss of 5-hydroxymethylcytosine in cancer: cause or consequence? Genomics: 104(5): 352-357.

35. Wang KC, Kang CH, Tsai CY, Chou NH, Tu YT, et al. (2018) Ten-eleven translocation 1 dysfunction reduces 5-hydroxylmethylcytosine expression levels in gastric cancer cells. Oncol Lett 15(1): 278-284. 
36. Huang ME, Ye YC, Chen SR, Chai JR, Lu JX, et al. (1988) Use of all-trans retinoic acid in the treatment of acute promyelocytic leukemia. Blood 72(2): 567-572.

37. Warrell RP Jr, Frankel SR, Miller WH Jr, Scheinberg DA, Itri LM, et al. (1991) Differentiation therapy of acute promyelocytic leukemia with tretinoin (all-trans retinoic acid). N Engl J Med 304(20): 1385-1393.

38. de The H, Pendolfi PP, Chen Z (2017) Acute promyelocytic leukemia: a paradigm for oncoprotein-targeted cure. Cancer Cell 32(5): 552-560.

39. Liau MC, Lee SS, Burzynski SR (1990) Modulation of cancer methylation complex isozymes as a decisive factor in the induction of terminal differentiation mediated by Antineoplaston A5. Intl J Tiss React 12 (Suppl): 29-36.

40. Liau MC, Liau CP, Burzynski SR (1992) Potentiation of induced terminal differentiation by phehylacetic acid and related chemicals. Intl J Exptl Clin Chemother 5: 9-17.

41. Jochem M, Ende L, Isasa M, Ang J, Schnell H, et al. (2019) Targeted degradation of glucose transporters protects against arsenic toxicity. Mol Cell Biol 39: 559-618.

42. Liau MC, Fruefauf PA, Zheng ZH, Fruehauf JP (2019) Development of synthetic CDA formulations for the prevention and therapy of cancer via targeting of cancer stem cells. J Cancer Studies Ther 4(1):1-15.

43. Gambacorti-Passerini C, Antolini L, Mahon FX, Guilhot F, Deininger M, et al. (2011) Multicenter independent assessment of outcomes in chronic myeloid leukemia patients treated with imatinib. J Natl Cancer Inst 103(7): 553-561.

44. Baker MJ, Brem S, Daniels S, Sherman B, Phuphanich S (2002) Complete response of a recurrent, multicentric malignant glioma in a patient treated with phenylbutyrate. J Neurooncol 59(3): 239-242.

45. BurzynskiSR, Nagy-KuboveE(2011)Treatmentofesthesioneuroblastoma and non-small cell-lung cancer with phenylbutyrate. J Cancer Ther 2(4): 518-522.

46. Burzynski SR, Tamicki TJ, Burzynski GS, Brookman S (2014) Preliminary findings on the use of targeted therapy with pazopanib and other agents in combination with sodium phenylbutyrate in the treatment of glioblastoma multiforme. J Cancer Ther 5(14): 1423-1437.

47. Burzynski SR, Burzynski GS, Brookman S (2015) A case of sustained objective response of recurrent/progressive diffuse intrinsic pontine glioma with phenylbutyrate and targeted agents. J Cancer Ther 6(1): 4044.

48. Stoner GD, Wang LS, Zikri N, Chen T, Hecht SS, et al. (2007) Cancer prevention with freeze-dried berries and berry components. Semi Cancer Biol 17(5): 403-410.

49. Amin AR, Kucuk O, Khuri FR, Shin DM (2009) Perspective for cancer prevention with natural compounds. J Clin Oncol 27(16): 2712-2725.

50. Wang LS, Hecht SS, Carmella SG, Yu N, Larue B, et al. (2009) Anthocyannin in black raspberries prevent esophageal tumors in rats. Cancer Prev Res (Phila) 2(1): 84-93

51. Allegra A, Innao V, Russo S, Gerace D, Alonci A, et al. (2017) Anticancer activity of curcumin and its analogues: preclinical and clinical studies. Cancer Invest 35(1): 1-22.

52. Liau MC, Szopa M, Burzynski B, Burzinski SR (1987) Chemosurveillance: a novel concept of the natural defense mechanism against cancer. Drug Exp Clin Res 13(Suppl 1): 77-76.

53. Liau MC, Szopa M, Burzynski B, Burzinski SR (1987) Quantitative assay of plasma and urinary peptides as an aid for the evaluation of cancer patients undergoing antineoplaston therapy. Drug Exp Clin Res 13(Suppl 1): 61-70.

54. Williamson PJ, Kruger AR, Reynolds PJ, Hamblin TJ, Oscier DG (1994) Establishing the incidence of myelodysplastic syndromes. Br J Haemato 87(4): 743-745.

55. Boula A, Voulgarelis M, Giannouli S, Katrinakis G, Psyllaki M, et al. (2006) Effect of CA2 antitumor necrosis factor- $\alpha$ antibody therapy on hematopoiesis of patients with myelodysplastic syndromes. Clin Cancer Res 12(10): 3099-3108.
56. Itkin T, Rafii S (2017) Leukemia cells "gas up" leaky bone marrow blood vessels. Cancer Cell 32(3): 276-278.

57. Passaro D, Di Tullio A, Abarrategi A, Rouault-Pierre K, Foster K, et al. (2017) Increased vascular permeability in the bone marrow microenvironment contributes to disease progression and drug response in acute myeloid leukemia. Cancer Cell 32(3): 324-341.

58. Counter CM, Gupta J, Harley CB, Leber B, Bacchetti S (1995) Telomerase activity in normal leukocytes and hematological malignancies. Blood 85(9): 2315-2320.

59. Fu C, Chen Z (2002) Telomerase activity in myelodysplastic syndrome. Chin Med J (Engl) 115(10): 1475-1478.

60. Delhommeau F, Dupont S, Valle VD, James C, Trannoy S, et al. (2009) Mutation in TET2 in myeloid cancers. N Engl J Med 360: 2289-301.

61. Larsson CA, Cote G, Quintás-Cardama A (2013) The changing mutational landscape of acute myeloid leukemia and myelodysplastic syndrome. Mol Cancer Res 11(8): 815-827.

62. Papaemmanuil E, Gerstung M, Malcovati L, Tauro S, Gundem G, et al. (2013) Clinical and Biological implication of driver mutations in myelodysplastic syndromes. Blood 122(22): 3616-3627.

63. Bejar R, Lord A, Stevenson K, Bar-Natan M, Pérez-Ladaga A, et al. (2014) TET2 mutations predict response to hypomethylating agents in myelodysplstic syndrome patient. Blood 124(17): 2705-2712.

64. Kennedy JA, Ebert BL (2017) Clinical implication of genetic mutations in myelodysplastic syndrome. J Clin Oncol 35(9): 968-974.

65. Woll PS, Kjällquist U, Chowdhury O, Doolittle H, Wedge DC, et al. (2014) Myelodysplastic syndromes are propagated by rare and distinct human cancer stem cells in vivo. Cancer Cell 25(6): 794-808.

66. Maeck L, Haase D, Schoch C, Hiddemann W, Alves F (2000) Genetic instability in myelodysplastic syndrome: detection of microsatellite instability and loss of heterozygosity in bone marrow sample with karyotype alteration. Br J Haemato 109(4): 842-846.

67. Xie D, Hefmann KW, Mori N, Miller CW (2001) Allotype analysis of the myelodysplastic syndrome. Leukemia 14: 805-810.

68. Kuramoto K, Ban S, Oda K, Tanaka H, Kimura A, et al. (2002) Chromosomal instability and radiosensitivity in myelodysplastic syndrome. Leukemia 16(11): 2253-2258.

69. Takada A, Goosby C, Yaseen NR (2006) Nup98-HOXA9 induces long term proliferation and blocks differentiation of primary human CD34+ hematopoietic cells. Cancer Res 66(13): 6628-6637.

70. Feng F, Li Q Ling CQ Zhang Y, Qin FZ, et al. (2005) Phase III clinical trials of the cell differentiation agent-2 (CDA-2): therapeutic efficacy on breast cancer, non-small- cell lung cancer, and primary hepatoma. Chin J Clin Oncol 2: 706-16.

71. Liau MC (2007) Pharmaceutical composition inducing cancer cell differentiation and the use for treatment and prevention of cancer thereof. US Patent 7232578 B2.

72. Santi DV, Norment A, Garrett CE (1984) Covalent bond formation between a DNA-cytosine methyltransferase of DNA containing 5-azacytosine. Proc Natl Acad Sci USA 81(22): 6993-6997.

73. Ma J (2007) Differentiation therapy of malignant tumor and leukemia. CSCO Treaties on the Education of Clinical Oncology 480-486.

74. Liau MC, Fruehauf JP (2015) Destabilization of abnormal methylation enzymes as a critical mechanism for CDA-2 to reverse MDS progression. The First International Forum of Myelodysplastic Syndrome in Tai Zhou, Jiangsu, China, 31-35.

75. Prassana P, Shack S, Wilson VL, Samid D (1995) Phenylacetate in chemoprevention of 5-aza-2'-deoxycytidine-induced carcinogenesis. Clin Cancer Res 1(18): 865-871.

76. Gaudet F, Hodgson JG, Eden A, Jackson-Grusby L, Dausman J, et al. (2003) Induction of tumors in mice by genomic hypomethylation. Science 300(5618): 489-492.

77. Palii SS, Van Emburgh BO, Sankpal UT, Brown KD, Robertson KD, et al. (2008) DNA methylation inhibitor 5-Aza-2'-deoxycytidine induces 
reversible genome-wide DNA damage that is distinctly influenced by DNA methyltransferases 1 and 3B. Mol Cell Biol 28(2): 752-771.

78. Yang Q Wu F, Wang F, Cai K, Zhang Y, et al. (2019) Impact of DNA methyltransferase inhibitor 5-azacitidine on cardiac development of zebrafish in vivo and cardiomyocyte proliferation, apoptosis, and the homeostasis of gene expression in vitro. J Cell Biochem 120(10): 1745917471

79. Knudson AG Jr (1971) Mutation and cancer: statistical study of retinoblastoma. Proc Natl Acad Sci USA 68(4): 820-823. 